\title{
The next step in surgical quality improvement: outcome situational awareness
}

\author{
William B. Lyman, MD \\ Michael Passeri, MD \\ Keith Murphy, MSPH \\ Allyson Cochran, MSPH \\ David A. lannitti, MD \\ John B. Martinie, MD \\ Erin H. Baker, MD \\ Brent D. Matthews, MD \\ Dionisios Vrochides, MD, PhD
}

Posters presented at ERAS USA First Annual Meeting, Dallas, TX, Nov 10-11, 2017; and Sixth ERAS World Congress, Stockholm, Sweden, May 23-25, 2018.

Accepted June 27, 2019

\section{Correspondence to:}

W.B. Lyman

Department of Surgery

Carolinas Medical Center

1000 Blythe Blvd, MEB Suite 601

Charlotte NC 28204

william.Lyman@carolinashealthcare.org

DOI: $10.1503 /$ cjs.000519

\section{SUMMARY}

A similar theme unites proposed solutions for stagnant improvement in outcomes and rising health care costs: eliminate unnecessary variation in the care of surgical patients. While large quality-improvement projects like the Americal College of Surgeons National Surgical Quality Improvement Program have historically led to improved patient outcomes at the hospital level, the next step in surgical quality improvement is to eliminate unnecessary variation at the level of the individual surgeon. Critical examination of individualized clinical, financial and patient-reported outcomes - outcome situational awareness - along with peer group comparison will help surgeons to identify variation in patient care. We are piloting an interactive software platform at our institution to provide information on individualized clinical, financial and patient-reported outcomes in real time through automatic data population of a central REDCap database. These individualized data along with peer group comparison allow surgeons to objectively determine areas of potential improvement.

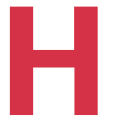

as surgical quality improvement reached a plateau? There was a time when surgery was the "Wild West." Dogma and individual preference ruled the care of surgical patients - and patients suffered. Although other quality-improvement projects existed before its inception with varying degrees of success, the introduction of the National VA Surgical Risk Study in 1991 was a landmark in patient care. The program that eventually became the American College of Surgeons National Surgical Quality Improvement Program (ACS-NSQIP) brought national outcomes and standards of care to the forefront of surgical discussion. By closely monitoring outcomes and comparing those outcomes to peer institutions, hospitals enjoyed lower complication rates by identifying areas of concern and addressing institutional issues in patient care. ${ }^{1}$ For many years, participation in ACS-NSQIP correlated with improved patient outcomes; however, the same benefit of ACSNSQIP adoption has not been realized by institutions recently. ${ }^{2}$ Have we reached the peak of our surgical ability, or have our methods for quality improvement become stagnant?

While we see a plateau in surgical outcomes, many countries have continued to see a massive increase in health care expenditure. While medical underuse remains an issue in some areas of the world, overuse and unnecessary spending is a real issue in others. ${ }^{3,4}$ In 2010 alone, the US Institute of Medicine estimated an annual excess cost from health care-related services at $\$ 765$ billon, $\$ 210$ billion of which was considered "unnecessary services." ${ }_{5}$ Studies comparing health care expenditure in equally matched patient populations show that increased spending does not correlate with improved patient outcomes, and "overuse" of medical resources can be detrimental to patients, both clinically and financially. ${ }^{6}$ 
Perhaps there is not a cause and effect relationship between the quality-improvement plateau and rising health care costs, but a similar theme unites proposed solutions for each: eliminate unnecessary variation in surgery and patient care. We believe that ACS-NSQIP and other national quality-improvement projects helped to eliminate large scale variance in system practices with large data sets, national averages and benchmarks. The next step in surgical quality improvement is to focus on individual surgeon variance in patient care.

\section{THE CONCEPT OF OUTCOME SITUATIONAL AWARENESS}

With the goal of improving the quality of patient care, we have recently focused on simultaneously evaluating 3 separate yet interconnected patient outcomes: clinical outcomes, financial outcomes and patient-reported outcomes (including patient satisfaction). Without a healthy balance among these outcomes, none can stand on their own. This balance and examination of the relationship among all 3 outcomes is termed "outcome situational awareness" (OSA). With the ever-present clinical and clerical responsibilities of the modern surgeon, is it reasonable or even possible for surgeons to know their individualized outcomes?

\section{AN INTERACTIVE SOFTWARE PLATFORM FOR OUTCOME SITUATIONAL AWARENESS}

While few surgeons can quote their exact clinical outcomes, it could be argued that even fewer can quote accurate financial or patient-reported outcomes. The level of detail and time required for surgeons to track and monitor all outcomes often require the help of research staff and statisticians; however, few surgeons have access to full-time research staff.

We are piloting an interactive software platform at our institution that provides surgeons with real-time updates for individualized clinical, financial and patient-reported outcomes. Real-time updates are made possible through automatic data population of a centralized REDCap database from the electronic medical record (clinical outcomes), administrative databases (financial outcomes) and interactive mobile applications (patientreported outcomes). Clinical, financial and patient-reported outcomes are then combined into a single OSA optimization index. In order to combine unlike variables between the 3 different types of reported outcomes into a single index, each variable was converted to standard deviation from the peer group mean. Variables are then weighted according to institutional preference. For example, at our institution clinical outcomes account for $50 \%$ of the index while financial and patient-reported outcomes each account for $25 \%$ of the index. The OSA optimization index can be tracked over time to ensure that improvement in a single patient outcome category (e.g., financial outcomes) is not improving at the expense of other outcome categories (e.g., clinical or patientreported outcomes).

Additionally, within the platform surgeons are able to compare their own outcomes in each category to those of their peers. Empowering surgeons with individualized outcome reports with peer group comparison allows surgeons to objectively determine areas for individual improvement. Finally, the OSA platform incorporates predictive algorithms to determine unexpected trends in outcomes, alerting surgeons to unexpected variance in patient care before it may be clinically apparent. With the OSA platform, updated clinical, financial and patientreported outcomes are instantly available to each surgeon with the click of a mouse (Fig. 1).

\section{Conclusion}

While bringing focus to individual surgeon outcomes may be uncomfortable and could initially be met with resistance, we must not lose sight that OSA will first and foremost benefit the patient. Just as hospital level outcomes benefited from peer group comparison in ACS-NSQIP, individual surgeons will benefit from comparison with their own peer group. No matter how accomplished a

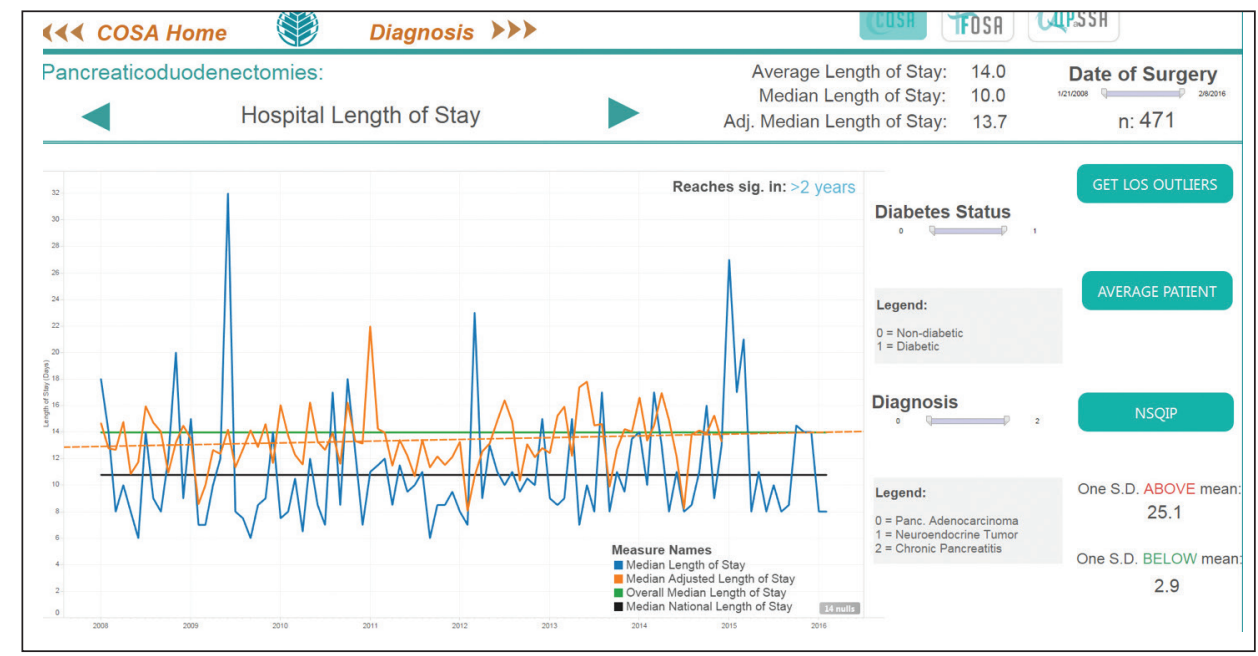

Fig. 1. Screenshot of interactive outcome situational awareness (OSA) software platform for monitoring pancreaticoduodenectomies. On this page, pancreaticoduodenectomy is selected as the procedure, clinical outcomes (COSA) are selected, and the specific outcome tracked is length of stay. 
surgeon is, there is always something new to learn from critical examination of her or his outcomes. Whether that learning is an operative technique to reduce hernia recurrence or a method to arrange a clinic schedule to improve patient satisfaction, either can be beneficial to a new or established surgeon. Outcome comparison with peers will help to identify variation in technique and patient care, targeting possible areas for improvement. By identifying peers who excel in certain areas, coaches can be identified to assist with improved outcomes. ${ }^{7}$ If updated clinical, financial and patient-reported outcomes are not enough to convince surgeons to critically examine individual variation in patient care, these are certainly the same categories by which prospective patients, hospitals and insurance companies will soon judge surgeons. ${ }^{8}$ The era of dogma is over. It is time to approach patient care with an evidencebased and data-driven mindset, a keen awareness of our own outcomes, and an eagerness for continued improvement in surgical quality with the help of OSA.

Affiliations: From the Department of Surgery, Carolinas Medical Center, Charlotte, NC (Lyman, Matthews); and the Division of HPB Surgery, Carolinas Medical Center, Charlotte, NC (Passeri, Murphy, Cochran, Iannitti, Martinie, Baker, Vrochides).

Competing interests: None declared.

Contributors: All authors contributed substantially to the conception, writing and revision of this article and approved the final version for publication. No other competing were declared.

\section{References}

1. Khuri SF, Daley J, Henderson WG. The comparative assessment and improvement of quality of surgical care in the Department of Veterans Affairs. Arch Surg 2002;137:20-7.

2. Osborne NH, Nicholas LH, Ryan AM, et al. Association of hospital participation in a quality reporting program with surgical outcomes and expenditures for Medicare beneficiaries. FAMA 2015; 313:496-504.

3. Saini V, Brownlee S, Elshaug AG, et al. Addressing overuse and underuse around the world. Lancet 2017;390:105-7.

4. Brownlee S, Chalkidou K, Doust J, et al. Evidence for overuse of medical services around the world. Lancet 2017;390:156-68.

5. Institute of Medicine Roundtable on Evidence-Based Medicine. The National Academies Collection. Reports funded by National Institutes of Health. In: Yong PL, Saunders RS, Olsen LA, eds. The Healthcare Imperative: Lowering Costs and Improving Outcomes: Workshop Series Summary. Washington (DC): National Academies Press (US) National Academy of Sciences; 2010.

6. Fisher ES, Wennberg DE, Stukel TA, et al. The implications of regional variations in Medicare spending. Part 1: the content, quality, and accessibility of care. Ann Intern Med 2003;138:273-87.

7. Greenberg CC, Dombrowski J, Dimick JB. Video-based surgical coaching: an emerging approach to performance improvement. 7AMA Surg 2016;151:282-3.

8. Department of Health and Human Services. The Quality Payment Program; 2018. Available: https://qpp.cms.gov/ (accessed 2018 Jan. 6). 